\title{
TECNOLOGIAS ASSISTIVAS E DEFICIÊNCIA: UM ENCONTRO DAS MULHERES-MÃES COM A FABRICAÇÃO DIGITAL NOS FAB LABS
}

\section{ASSISTIVE TECHNOLOGIES AND DISABILITY: A GATHERING BETWEEN WOMEN- MOTHERS AND DIGITAL FABRICATION IN FAB LABS}

\author{
Juliana Maria Moreira Soares ${ }^{1}$, Paulo Eduardo Fonseca de Campos ${ }^{1}$
}

\section{RESUMO:}

O espaço que as novas tecnologias têm ocupado no cotidiano das pessoas é cada vez mais amplo. No entanto, tal ocupação não tende a ser democrática e igualitária. Partindo desse olhar, o presente artigo tem como objetivo apresentar percepções a respeito das vivências realizadas em um projeto desenvolvido sobre os seguintes pilares: mulheres-mães, deficiência e desenvolvimento de Tecnologia Assistiva em espaços conhecidos como Fab Labs. Através de uma abordagem de cunho exploratório e natureza qualitativa, este estudo introduz um panorama da pesquisa, seguido das explorações e reflexões sobre as atividades de campo realizadas. Em suas etapas práticas, entre outros momentos, foram utilizados métodos de caráter etnográfico e Design Research. O grupo focal de mulheres, mães de crianças com deficiência, cujo número de integrantes foi variável durante as práticas (de duas a cinco pessoas), realizou atividades de desenvolvimento de produtos de tecnologia assistiva utilizando ferramentas de manufatura digital em um laboratório público da Rede Fab Lab Livre SP, na cidade de São Paulo, Brasil. As reflexões deste estudo se relacionam com as questões de interpretação dos significados das atividades nesses espaços para o grupo e suas identificações com as tarefas tecnológicas performadas. Dessa forma, procura-se contribuir para um debate com relação à ocupação de ambientes do tipo Fab Lab, vocacionados a uma entrada social e plural de seus usuários e usuárias.

PALAVRAS-CHAVE: mulheres; deficiência; Fab Labs; projetos; fabricação digital.

\section{ABSTRACT:}

The space that new technologies have occupied in people's daily lives is increasingly broad. However, such occupation does not tend to be democratic and egalitarian. From this perspective, this article aims to present perceptions about the experiences carried out in a project developed on the following pillars: women-mothers, disabilities and the development of Assistive Technology in spaces known as Fab Labs. Through an exploratory and qualitative approach, this study introduces an overview of the research, followed by explorations and reflections on the activities carried out. In its practical steps, among others, ethnographic and Design Research methods were used. The group of women, mothers of children with disabilities, whose number of members varied during the practices (from two to five people), carried out activities to develop assistive technology products using digital manufacturing tools in a public laboratory of the Rede Fab Lab Livre SP, in São Paulo, Brazil. The thoughts and analysis presented on this piece of study are related to the questions of interpretation of the meanings of the activities in these spaces for the group and their identifications with the performed technological tasks. In this way, we seek to contribute to a debate regarding the occupation of environments of the Fab Lab type, focused on a social and plural participation of its users.

KEYWORDS: women; disability; Fab Labs; projects; digital fabrication.
1 Universidade de São Paulo

Fonte de Financiamento: Não houve.

Conflito de Interesse: Declara não haver.

Ética em Pesquisa: Esta pesquisa está aprovada no Comitê de Ética em Pesquisa (CEP - Plataforma Brasil), sob o CAAE 70080217.0.0000.5504.

Submetido em: 28/02/2021 Aceito em: 28/08/2021 


\section{INTRODUÇÃO}

Um dos grandes desafios dentro do campo de produção de ciência e tecnologia, no sentido das epistemologias abarcadas em seu processo de construção, talvez seja a promoção de convergências ou dos encontros. Tais encontros, por sua vez, tendem a estabelecer novos cenários, a partir de preenchimentos e da reparação de lacunas históricas. Nessa linha, é necessário reconhecer que, apesar dos avanços observados nos mais diversos âmbitos, a sociedade da informação permanece há muito alicerçada sobre uma complexa questão, no tocante à real democratização do acesso às múltiplas tecnologias por parte das minorias políticas, como as comunidades de baixa renda, as pessoas não-brancas, os indivíduos com deficiência e as mulheres, sendo esses dois últimos os públicos protagonistas do presente estudo. Trata-se de uma pauta multifacetada, podendo ser analisada sob diversos ângulos, indo do momento conceptivo destes projetos ao agenciamento humano sobre as tecnologias consideradas, estando todas essas etapas conectadas e em convívio com as exclusões sistemáticas dos setores sociais mencionados. Esses aspectos convocam à necessidade de reflexões críticas mais detidas, que possam levar a um reposicionamento das ofertas tecnológicas em favor desses grupos.

Dessa forma, é notável o fato de que ambientes de produção tecnológica sejam espaços historicamente alijados da presença feminina e de outros grupos sociais específicos, e que, não raramente, tais espaços destacam-se pela invisibilização do trabalho de mulheres que tiveram atuação nesse campo. Não são escassas as narrativas de apagamento a respeito das realizações protagonizadas por mulheres, as quais posteriormente foram vinculadas às figuras masculinas, como parceiras e colegas de trabalho. Esse tema vem se materializando na sociedade e produtos audiovisuais acessíveis já tratam do tema na atualidade, como os filmes Estrelas Além do Tempo (2017) e Ammonite (2020), que trazem histórias de importantes mulheres cientistas e pesquisadoras as quais passaram por esse processo de invisibilização. A pergunta "por que tão poucas?" (FAULKNER, 2001, p. 79) é um constante ponto de partida das mais diversas análises feitas dentro dessa seara de estudos, da abordagem filosófica ao enquadramento epistemológico do assunto. A representação simbólica do ser humano atrelado ao desenvolvimento de tecnologia e ciência ainda carrega um forte estereótipo do sujeito masculino, de meia idade, temperamental e de postura intocável dentro de seu laboratório. A partir desse olhar de produção tecnológica na sociedade, ressalta-se a forma como a manufatura digital vem ganhando relevo na contemporaneidade, particularmente sob a forma de laboratórios de fabricação digital, mais comumente conhecidos nos dias atuais como Fab Labs, sendo esses espaços possíveis e viáveis aos processos de desenvolvimento de tecnologia, cuja proposta inclusive excede o campo do capital privado e já integra o corpo de estratégias de políticas públicas em cidades de grande porte.

Como explorar esses espaços para que os mesmos não sejam apenas uma mera reprodução da cultura hegemônica é um dos pontos a serem questionados quando se realizam abordagens dessa natureza. Neste artigo, busca-se trazer reflexões sobre mecanismos de colaboração e visualização sistêmica dos processos dentro de espaços do tipo Fab Lab, os quais, apesar de uma presença constante de determinados grupos e perfis, guardam potência e ressonância suficientes em atividades capazes de envolver públicos habitualmente pouco presentes em tais ambientes. Assim, através de vivências e contextos imersivos em meio a públicos com deficiência físico-motora e suas cuidadoras - aqui representadas pelas figuras maternas, - e em consideração às premissas anteriormente expostas, desenvolve-se o eixo propositivo deste estudo. Orientada por um contexto de escassez dentro do cenário de oferta de produtos da área de Tecnologia Assistiva (TA) no Brasil, formulou-se a perspectiva de engajar grupos de mulheres intimamente relacionadas à temática da deficiência (aqui as mães de crianças com deficiência físico-motora) dentro da área de tecnologia, usando como suporte a fabricação 
digital voltada ao desenvolvimento de objetos assistivos em conformidade com suas demandas cotidianas sinalizadas.

Dessa forma, o levantamento das potencialidades e a observação das fragilidades a partir da imersão desse grupo em ambientes vocacionados à inovação e produção tecnológica, como são os Fab Labs, é um dos objetivos desta pesquisa. 0 grupo de mães em referência faz parte de uma organização não-governamental (ONG) que desempenha atividades de inclusão e socialização de crianças com deficiência através da prática esportiva. A seguir, serão expostos os conceitos compreendidos pelo presente estudo, de cunho exploratório e qualitativo, cujos resultados parciais obtidos foram extraídos a partir de abordagens que mesclam métodos oriundos da natureza do design e das ciências sociais. 0 presente artigo, por sua vez, constitui parte das reflexões trazidas pela pesquisa de doutorado de sua primeira autora, a qual atualmente se encontra em fase de conclusão.

\section{PROCEDIMENTOS METODOLÓGICOS}

Os resultados deste estudo aqui apresentados são frutos de um processo de mais de dois anos de vivências entre a pesquisadora e primeira autora do presente artigo, e o coletivo de mulheres-mães aqui identificado como grupo focal. As trocas se iniciaram nos ambientes de encontro das mães (a supracitada ONG) no ano de 2017. As ações de pesquisa tiveram prosseguimento nos laboratórios da Rede Fab Lab Livre SP, nos quais ocorreram as etapas empíricas do processo, entre os anos de 2018 e 2019. Neste processo foram feitas entrevistas, aplicados questionários e realizadas observações-participantes, a partir de interações espontâneas ocorridas de acordo com os ciclos de desenvolvimento de produtos e a produção experimental de artefatos. As atividades do grupo foram documentadas por meio de registros escritos, orais e da captura de imagens, todos estes materiais obtidos mediante o prévio consentimento das participantes. Dessa forma, foram utilizados recursos provenientes de métodos etnográficos, da Pesquisa Narrativa e do Design Research para a produção de tais interações, na medida em que tais metodologias e técnicas de pesquisa possuem um elevado nível de convergência quando se trata do envolvimento com grupos sociais, capazes de gerar a qualidade aspirada tanto na fase de coleta como de tratamento de dados, de modo a fundamentar posteriormente as análises dos experimentos desenvolvidos com mães e filhos. Os relatos obtidos a partir dessas vivências foram analisados e relacionados a teorizações sobre educação, tecnologia e gênero, segundo as perspectivas formuladas por autores como Paulo Freire (1996, 2018), Cheryl Buckley (1986) e Wendy Faulkner (2001). A escolha do grupo participante das atividades finais em laboratório ocorreu com base no acesso integral da pesquisadora e primeira autora deste artigo às ações da ONG mencionada, sendo realizada a partir da adesão voluntária das mães, que manifestaram seu interesse em participar no processo proposto por meio do preenchimento dos questionários iniciais que precederam a realização dos experimentos de caráter mais empírico.

\section{A TECNOLOGIA AO ENCONTRO DA DEFICIÊNCIA: A TECNOLOGIA ASSISTIVA (TA)}

Ainda não muito popularizada no País, a Tecnologia Assistiva é o campo que trata do desenvolvimento de bens materiais e serviços voltados às pessoas com deficiência. Essa atribuição específica foca em proporcionar maiores graus de autonomia e independência aos seus usuários, através de sua interação com tais ferramentas (BERSCH, 2017). Uma reclamação constante do público que faz uso desses recursos refere-se ao capacitismo ${ }^{i}$ das propostas conectadas a essas tecnologias que, por momentos, parecem buscar a "cura" do indivíduo (ficando subjacente aqui um referencial conectado aos modelos médicos da deficiência) e não 
o potencializar de suas capacidades. Ainda, apesar da essencialidade desses equipamentos para parcelas dessa população, com frequência são apontadas inadequações generalizadas, como a falta de customização funcional, altos custos de obtenção, dificuldade de acesso por meio de políticas públicas e a insatisfação estética (CRUZ, EMMEL, 2012; HAMIDI et al., 2018).

É relevante comentar que a população com deficiência está presente em um nível expressivo no País. No Brasil há aproximadamente 45 milhões de pessoas que declaram deficiência, resultando em $23,9 \%$ da população, de acordo com o último censo realizado em território nacional (IBGE, 2012). Para o presente recorte, é importante trazer que dentro desses números há uma porcentagem de crianças (menores de 14 anos de idade) que chega a 7,5\% desse total de indivíduos. Em muitas das famílias com crianças com deficiência, as mães desempenham papel fundamental na atenção integral a elas, abandonando por vezes suas carreiras e afazeres externos ao papel de cuidadora. Dessa forma, torna-se importante somar a esse quadro o fato de que o abandono parental, ou o afastamento da figura paterna com relação ao nascimento de uma criança com deficiência na família, registra-se como um fenômeno frequente (LAMB, BILLINGS, 1996; VENDRUSCULO, 2014).

São múltiplas as formas de visibilizar a agenda da inclusão nas comunidades, sendo esta uma pauta recorrente e mais que urgente na atualidade. Em uma dessas linhas estaria a abordagem através dos meios de produção tecnológica, sob os quais se percebe que, como em outras estruturas da sociedade, são reproduzidas as bases de exclusão de segmentos sociais diversos, de maneira sistêmica. Aqui, então, são elucidados diversos níveis desse processo de segregação, e tal qual um registro disso, pode-se citar como o distanciamento das pessoas com deficiência e demais usuários relacionados aos recursos assistivos dentro desses ciclos incorre em aspectos complexos relacionados à emergência dessas tecnologias. Decerto tais estruturas têm suas raízes fincadas em locais mais densos e profundos, residentes, por exemplo, no acesso à educação e às políticas sociais voltadas às comunidades vulneráveis. No entanto, é válida essa mirada atenta aos processos de recente emergência, como é o caso da consolidação desses espaços conhecidos como Fab Labs, os quais cada vez mais vêm ganhando ressonância e sendo visualizados como potências às organizações públicas, e suas relações com os grupos destacados.

\section{ESPAÇOS DE FAZER: OS FAB LABS}

Ambientes voltados à criação e à exploração dos conhecimentos não são novidades nas vivências cotidianas. Dos antigos ateliês aos espaços hackers, o que se evidencia nessa esfera é a existência de uma busca do ser humano por compartilhamento de saberes, encontro de novos formatos e de experiências de interação, inerentes ao processo da vida em sociedade. Assim, os laboratórios do tipo Fab Lab poderiam ser enquadrados nesse mesmo estrato, como espaços voltados ao fazer experimental, em meio a grupos de indivíduos com interesses em comum, junto às máquinas ali disponibilizadas. Portanto, esses locais também são os meios responsáveis por acolherem as atividades realizadas nessa pesquisa, que promovem a interlocução entre as mães, a produção de Tecnologias Assistivas e o acesso às máquinas de fabricação digital.

Os Fab Labs são territórios ocupados por uma diversidade de dispositivos, indo de ferramentas analógicas a impressoras tridimensionais e cortadoras a laser,estas últimas também conhecidas como máquinas de Comando Numérico Computadorizado, ou tão somente CNC, acrônimo pelo qual foram popularizadas. Trata-se de um modelo surgido e consolidado nos Estados Unidos, a partir da experiência que tomou forma no Center for Bits and Atoms (CBA), dirigido pelo professor Neil Gershenfeld, dentro do Massachusetts Institute of Technology (MIT). Gershenfeld, visto hoje por muitos como o "pai dos Fab Labs", à época lecionava uma 
disciplina que deu origem a esse formato de espaço, que abarcaria as múltiplas possibilidades produtivas oferecidas pela manufatura digital, com o intuito de desenvolvimento projetual entre os seus participantes. Nascida em 1998, a disciplina leva o nome de How to Make (Almost) Anything (Como Fazer [quase] Tudo), e ainda hoje é oferecida no MIT. Dessa maneira, o formato Fab Lab ganhou corpo neste contexto, ecoando a utilização da tecnologia de ponta em cenários similares ao longo da primeira década dos anos 2000, dentro e fora dos EUA, com finalidades educacionais e inovadoras, além do estímulo ao empreendedorismo (GERSHENFELD, 2012). No ano de 2020, o mesmo curso foi oferecido através de modalidade virtual e com adaptações.

A natureza dos Fab Labs é múltipla, podendo estes serem locais privados, públicos, universitários, entre muitas outras tipologias. 0 nome Fab Lab refere-se, formalmente, a um laboratório de fabricação digital filiado à rede mundial coordenada pela Fab Foundation. Conectar-se a essa malha, que hoje integra mais de 1750 espaços em diferentes países, depende do cumprimento de uma série de condições, a exemplo do respeito à chamada Fab Charter (um documento que contém os princípios de funcionamento do laboratório, o qual geralmente fica exposto em algum lugar visível do ambiente e/ou está disponibilizado em seus espaços virtuais) (FAB FOUNDATION, s/d). No entanto, a nomenclatura Fab Lab é utilizada como um denominador comum a essa espécie de ambiente, sendo muitas vezes aplicada a locais que não são filiados à rede global.

No Brasil, o primeiro laboratório vinculado à rede mundial Fab Lab foi o Fab Lab SP da Faculdade de Arquitetura e Urbanismo da Universidade de São Paulo (FAU-USP), implantado no ano de 2011. Após essa primeira iniciativa, outras unidades privadas e institucionais surgiram no País até a chegada da rede pública paulistana Fab Lab Livre SP. Tal rede foi criada no município de São Paulo no ano de 2015, mas seu vínculo com a malha global somente ocorreu em 2019. A implementação da rede está inserida dentro de um escopo de políticas públicas da cidade de São Paulo, Brasil. Difundir a tecnologia de fabricação digital voltada às práticas de cunho social, alavancando conjuntamente ações na esfera do microempreendedorismo e da inovação social foram algumas das perspectivas buscadas com a criação do projeto. Os resultados têm se mostrado positivos até o momento, envolvendo a territorialização da tecnologia com base na produção de conhecimentos, viabilizados através de diálogos transversais entre os saberes das comunidades locais e as estruturas técnicas desses ambientes, incluindo projetos na área de Tecnologia Assistiva. Atualmente, já são treze os laboratórios que conformam a rede municipal Fab Lab Livre SP, constituindo-se em espaços de usufruto público, gratuito e adeptos do uso de softwares livres (CHIOVETTI, 2017). Os espaços estão dispersos pelo município de São Paulo, atingindo regiões periféricas e limítrofes da cidade, geralmente pouco atendidas por políticas públicas e carentes em equipamentos culturais.

Tendo em vista o caráter público e a vocação social da rede Fab Lab Livre SP, as unidades dessa rede municipal foram os locais escolhidos para o desenvolvimento da base empírica da pesquisa, mais especificamente, para a realização de suas etapas experimentais. Nestes ambientes, entre 2018 e 2019, o grupo de mães e seus filhos foi convidado a realizar um ciclo inicial de experimentos dedicados a uma breve formação teórica sobre desenvolvimento de produtos e sua posterior manufatura, empregando-se para tanto a fabricação digital e outras máquinas convencionais disponíveis nos locais. Na Figura 01 é mostrado o processo desenvolvido junto ao coletivo: 
Figura 1. Imagem ilustrativa do ciclo de atividades inicialmente proposto às mães dentro da Rede Fab Lab Livre SP.

Fonte:

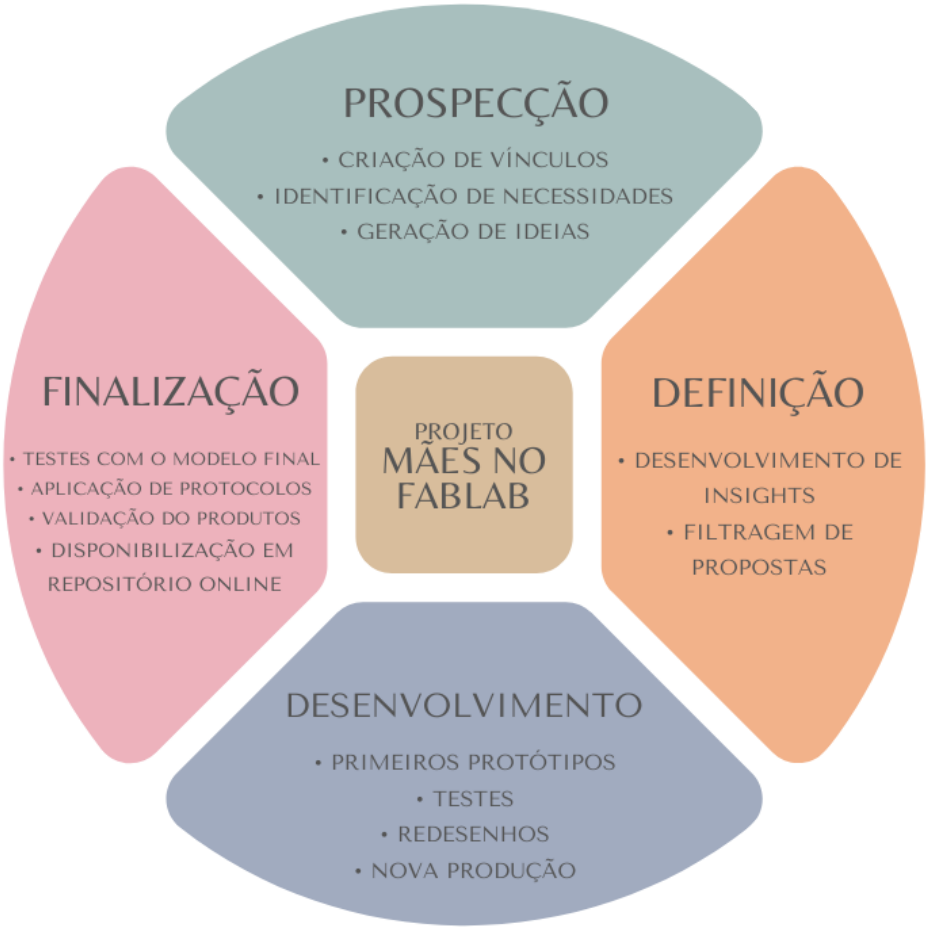

\section{EXPERIMENTANDO JUNTAS: TÃO PERTO, TÃO LONGE}

Nesse recorte da pesquisa, é proposto um olhar a respeito das presenças nos locais de realização das práticas. Aqui o lugar de análise se volta aos contornos materiais e imateriais dos conceitos de distância e proximidade incluídos nessa experiência. Quando se fala da alta capilaridade territorial da rede Fab Lab Livre SP, entende-se sua importante conexão com zonas a serem tocadas por esses equipamentos públicos, em territórios que, com frequência, sofrem com a escassez de opções nesse sentido, conforme já mencionado. No entanto, uma vez em campo e tecendo as tramas da pesquisa, percebia-se que, mesmo com a dispersão territorial desses equipamentos sociais nos diferentes pontos da cidade, eram poucas as pessoas que tinham conhecimento sobre sua finalidade e quais as máquinas ali podem ser encontradas. No grupo das mães, somente uma delas, Ana Santos, sinalizava que já conhecia de nome a iniciativa (tendo visto através da televisão algumas notícias relacionadas às atividades realizadas na rede). Outras companheiras de atividades comentaram também que já haviam passado por perto e visto alguns desses locais, mas não tinham entendido muito bem do que se tratava. Trazendo algo da vivência pessoal da primeira autora do presente artigo, em contato com outros colegas que estão conectados a outros conteúdos tecnológicos ou trabalham em áreas que potencialmente dialogam com esses campos (como a do audiovisual), pôde-se perceber que a falta de conhecimento sobre os laboratórios públicos era algo relativamente comum. Dessa forma, visualiza-se que o simples fato de acessar essa existência da rede, portanto, já constitui por si só uma inicial experiência positiva, assim como foi percebido pelo grupo de mães. Tão perto, tão longe.

Mesmo com a grande atividade nas redes sociais e com importantes eventos promovidos em locais estratégicos da cidade, como a SP Maker Week ii, a descoberta do pouco acesso/conhecimento sobre os espaços e ações da rede por parte da população foi algo notável 
durante os anos em que foi desenvolvida a pesquisa. Esse gargalo é reconhecido também por técnicos e instrutores que trabalham nos laboratórios, conforme reportado em conversas e entrevistas conduzidas. Tal situação chama a atenção para a necessidade de se promover estratégias mais permeáveis aos diversos públicos com interesse nas ações desse tipo de equipamento cultural, os quais potencialmente abrangem um grande espectro de perfis, para além dos já conhecidos usuários desses espaços.

Ressalte-se aqui que esse tema é visibilizado dentro das ações da rede. Trata-se de um assunto de interesse e atenção da coordenação da rede municipal local, e aqui é recordada uma das atividades realizadas na última SP Maker Week, ocorrida no ano de 2019, da qual participaram os autores. A prática em destaque no evento se constituiu numa espécie de simulação de um pitch voltado às soluções de promoção das ações da rede. Na oportunidade foi observada como essa chance de expansão das fronteiras caminha em aderência com a interlocução comunitária, a partir do significado distinto de acesso e contato junto aos espaços para os diversos grupos sociais. Ainda que ali não se estivesse com a representatividade ideal para gerar uma amostra fidedigna do público-alvo para a ocupação dos laboratórios, a presença de funcionários dos equipamentos públicos localizados nas periferias (como telecentros), de estudantes de áreas diversas e de pesquisadores permitiu alguma visualização mais ampla sobre as estratégias de comunicação necessárias, as demandas por acesso e as oportunidades para se aperfeiçoar a experiência. Como exemplo, um dos modelos de comunicação saídos dessa dinâmica foi uma espécie de "carro da pamonha" - um veículo com alto-falantes que percorre as periferias para a venda de pamonhas de milho - comunicador do Fab Lab Livre S, algo pouco visto na moderna gênese de centros urbanos dos dias atuais, porém ainda muito comum nas regiões periféricas e nas cidades do interior.

Voltando à experiência com o coletivo de mães, pontua-se que as mulheres do grupo levavam uma bagagem imensa para todas as atividades, dos primeiros encontros, ainda na ONG, às práticas conduzidas nos laboratórios, fase na qual o grupo se reduziu em tamanho. Com frequência se dialogava sobre suas histórias, seus afazeres e lazeres, em todos esses momentos. Em uma primeira atividade feita na ONG, voltada ao conhecimento do grupo e à criação de vínculos entre a pesquisadorae as mães, foram notáveis as descobertas sobre o que cada uma delas mais gostava de fazer longe dali (Figura 02). Ao final, Patrícia Goloni, coordenadora da ONG receptora desta pesquisa, comentou que, mesmo convivendo com as mães há anos, não conhecia muitos dos hobbies delas e das crianças, como bordar, ler e contar histórias. Existiam muitos encontros e proximidades. E entre essas práticas estavam múltiplas ocupações ligadas às mãos, ao artesanal e às ações de criação dos entornos do cotidiano, que se ligariam com esses afazeres dentro do próprio Fab Lab Livre SP. 
Figura 2. Atividade de criação de vínculos realizada com o grupo maior de mães ainda na ONG.

Fonte: Autora

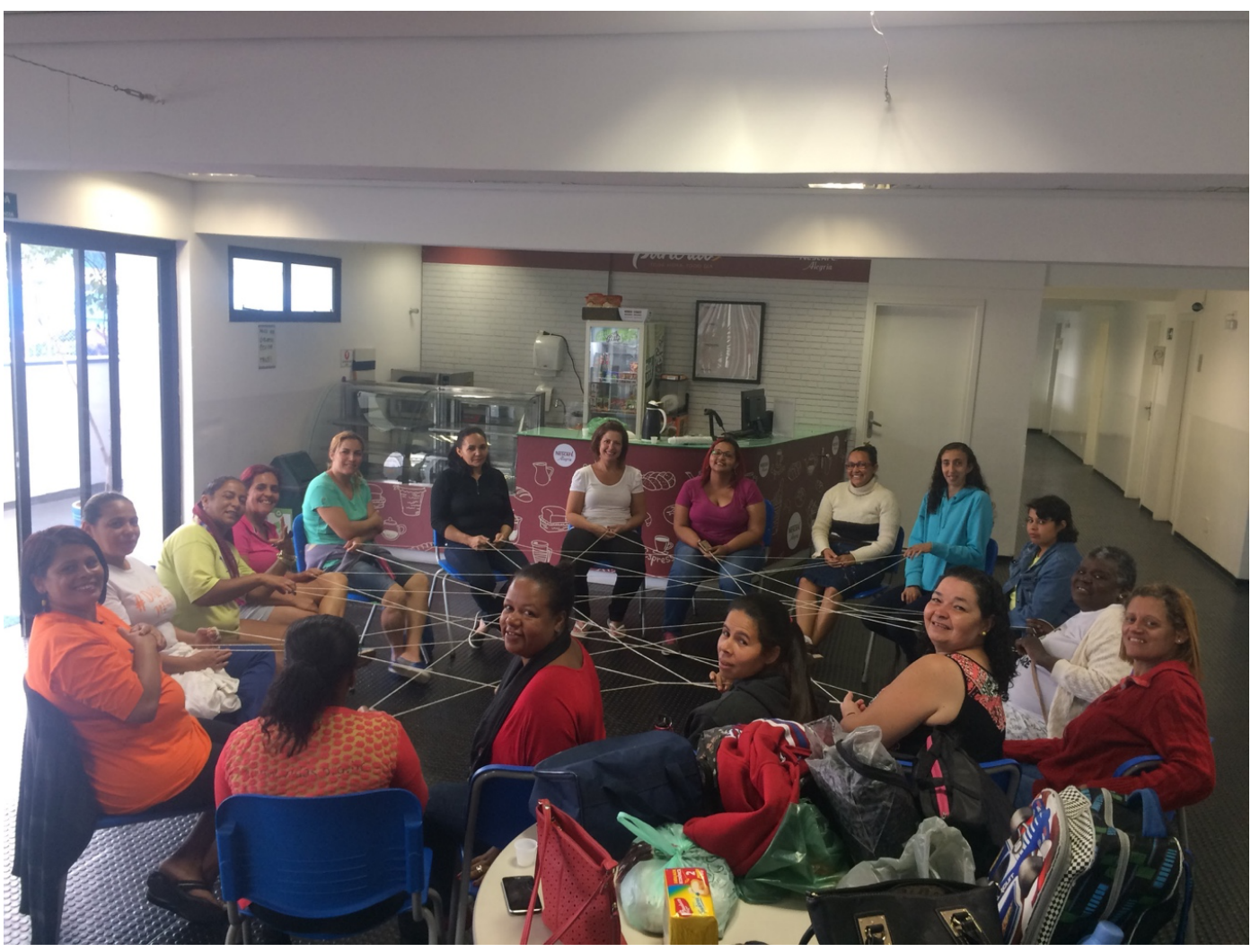

Pode ser dito que a tecnologia em suas diversas formas sempre esteve presente na perspectiva prática e simbólica da natureza humana, e, obviamente, não era diferente em nosso grupo. A falta de contato e conexão com aspectos tecnológicos, que por vezes se deixava entrever nas trocas, ficou evidente a partir do entendimento de que a tecnologia se constituía ali em "computador e máquinas, que nunca vi nada igual na vida" e "programas [softwares] diferentes"., ou seja, ao se falar de tecnologias de ponta dentro do senso predominante na sociedade de nosso tempo histórico. Essas percepções são válidas e importantes para a perspectiva de uma recente construção tecno-social sobre o cenário, afinal, conforme já relatado, trata-se de um universo de novidades e com graus diversos de complexidade para o entendimento coletivo. Acrescente-se a isso o fato de, ao se examinar dinâmicas socialmente estruturadas através da divisão generizadaiii do trabalho, as quais autoras relacionadas à seara de ciência e gênero iriam trazer à mesa como pilares interligados à desvalorização da seara manual dos trabalhos (em muito condicionados ao ambiente doméstico), compreende-se também parte do enraizamento dessa lógica que nos é comum (BUCKLEY, 1986; PERROT, 2007). 0 não visualizar das tecnologias de natureza doméstica e rotineiras como tecnologias de fato, que requerem procedimentos baseados em saberes e raciocínios lógicos, pode-se concluir então, constitui parte significativa desse processo de desligamento e crônico desencorajamento/desvalorização das performances cotidianas nestes ambientes.

Assim, ao lado dessas distâncias, os reconhecimentos também emergiram durante as jornadas. 0 recordar de outras experiências de trabalho era um desses despertares valiosos em termos práticos e afetivos, ao se avaliar que boa parte das mães do grupo havia deixado suas práticas profissionais para estarem mais próximas de seus filhos. Logo, nessa via, a reflexão segue novamente no sentido de proposição de estruturas que criem lembrança e proximidade com o universo desse público a partir da valorização e identificação dos saberes desses grupos em seus múltiplos atributosiv. Torna-se também essencial a construção de projetos que integrem e fomentem a criação de perspectivas críticas aos seus coletivos. Traduz-se, então, no fazer por 
entre estas máquinas e estruturas, em locais de possíveis encontros, dando suporte à prática formadora como experiência de reconhecimento e liberdade à construção de suas realidades e exploração de seus temas fundamentais (FREIRE, 1996).

Como componente desse processo dialógico, vale ressaltar a experiência de Amélia Souza, uma das mulheres que integrou essa jornada. Amélia é uma desenvolvedora amadora dentro dos ambientes da rede Fab Lab Livre SP e uma mulher com deficiência físico-motora. Moradora de uma região periférica de São Paulo, a qual possui um desses laboratórios públicos, Amélia desenvolvia tecnologias assistivas voltadas a si e aos moradores de seu bairro, além de outras espécies de tecnologias para o seu cotidiano. A dona de casa e desenvolvedora esteve presente no início das atividades com as mães, que relataram uma surpresa positiva imensa e inspiração ao constatarem suas experiências. Dessa forma, os relatos de Amélia traziam essa relação sobre as convergências vindas a reboque das práticas: o maior contato com sua comunidade, o reencontro com aprendizados, a melhora de seu estado de saúde mental e a importância dos aparelhos culturais ali na região eram alguns dos aspectos com frequência frisados. E aos poucos isso também se revelava no grupo, gerando uma consciência de proximidade que ia dos limites tangíveis (localização, uso dos recursos e possibilidades projetuais) aos intangíveis (capacidade, ocupação e identidade com o espaço).

\section{PROJETOS E PROJEÇÕES EM ANDAMENTO}

Pensando em desdobramentos e caminhos possíveis de extensão do presente projeto, foram buscadas iniciativas que dialogassem com as ideias desenvolvidas na pesquisa. Assim, especificamente aqui, aborda-se com maior ênfase a questão de gênero, com foco na inserção de mulheres em campos tecnológicos. Iniciativas nesta via de aproximação de tais grupos nas áreas de ciência e tecnologia aos poucos se popularizam ao redor do mundo. A organização sem fins lucrativos Girls Who Codev talvez seja uma das mais conhecidas em tal linha, ainda que não atinja uma grande porção do sul do planeta (envolve atualmente ações nos Estados Unidos, na Europa e na Índia). Em um horizonte de territorialização e agenciamento a partir das demandas e saberes locais, joga-se luz em ações nacionais que podem servir como inspiração ao alicerçamento de outras iniciativas e parcerias dentro da rede. Citam-se ainda os projetos Minas Programam ${ }^{v i}$ e PretaLabvii, os quais realizam ações de capacitação e ciclos de formação na área de programação para mulheres, com prioridade às mulheres negras. Outro caso que cabe ser citado, circunscrito nesses espaços da fabricação digital, são os laboratórios que possuem iniciativas específicasvoltadas às mulheres, como a exemplo do projeto abrigado pelo Fab Lab Recife chamado de Movimento Mulheres Maker (MMM) viii. Trata-se de uma iniciativa realizada por mulheres e apoiada por instâncias não-governamentais voltadas ao desenvolvimento comunitário, visando ao despertar do interesse e à ocupação destes ambientes por parte de mulheres de comunidades socialmente vulneráveis.

A partir de tal paradoxo da proximidade (geográfica, de presença dos aparelhos nos territórios) e do distanciamento (a respeito do universo tecnológico e de abismos sociais), soa valiosa a proposição de diálogos e pontes entre os saberes através dessas iniciativas, provocando possíveis encontros (e desencontros, possibilitando assim novas construções através da visibilização das fraturas nestes momentos iniciais). Cabe ressaltar ainda que, no percurso etnográfico da pesquisa, uma das estratégias adotadas foi o acompanhamento da produção de conteúdo nas redes sociais por parte de inúmeras iniciativas, como as citadas, com foco nas ações relacionadas ao ambiente nacional. Com maior frequência, são engendradas discussões e exposição de dados que abarcam perspectivas transversais às temáticas, cruzando mais comumente as lâminas de gênero, raça e condições socioeconômicas. A ênfase na estruturação de um pensamento crítico sobre a inserção desses públicos em tais âmbitos é percebida como um ponto nodal dentro das ações. Entende-se que, em uma sociedade tão 
profundamente marcada e alicerçada por estruturas assimétricas ${ }^{\mathrm{ix}}$, a entrada de públicos diversificados (e assim, identitarismos) per se talvez não se conjugue como um fator eliciador de mudanças instantâneas, mas sim causem reverberação enquanto presenças politizadas nesses espaços - desperta-se desse ponto a importância de tal processo de construção informativa/politizadora em conjugação com as ações práticas.

A respeito de tais atividades, de maneira bastante breve cita-se novamente que a rede paulistana Fab Lab Livre SP já possui iniciativas que visam à diminuição da brecha de gênero, desenvolvidas a partir de demandas internas e externas. Por exemplo, são realizadas atividades regulares e cursos com turmas de marcenariax, Arduíno e eletrônica voltadas exclusivamente a mulheres, sendo essas práticas também desenvolvidas e conduzidas por pessoas identificadas com o gênero feminino. Sobre a questão da deficiência, a metodologia de Emprego Apoiado adotada por parte da ITS Brasilxi propõe experiências de empregabilidade e capacitação ao público com deficiência dentro dos espaços geridos pelo institutoxii. A partir de associações com políticas estaduais e municipais de inclusão, o relatório anual da rede exibe métricas extensas com relação ao tema, porém ainda pouco específicas com relação ao impacto pontual na rede de laboratórios. A iniciativa era bastante comentada pelos funcionários locais como uma oportunidade de incluir públicos pouco abraçados pelo mercado, gerando experiência e aumentando a probabilidade de futura empregabilidade às pessoas participantes. Nas visitas aos espaços da rede, nas unidades frequentadas por esta pesquisa, não tivemos a oportunidade de encontrar trabalhadores contratados através desse projeto.

\title{
IDENTIDADES: O EU É FORMADO POR VÁRIOS EUS
}

\begin{abstract}
Quando nós entendemos que compartilhamos não apenas as moléculas básicas da vida, mas também os princípios elementares de organização com o restante do mundo vivo, percebemos o quão firme estamos costurados em todo o tecido da vida (Fritjof Capra, físico e ambientalista, em entrevista sobre os caminhos da pandemia dada em agosto de 2020). xiii
\end{abstract}

Seguindo esse percurso e encarando o quadro de apagamento das fontes, a generização ${ }^{\text {xiv }}$ das estatísticas desponta como uma das ferramentas que se consolidam, então, para a geração de um quadro favorável às análises situacionais (PERROT, 2007). Assim, trazer à tona o aspecto da incorporação de mais ciclos formativos basilares remonta a uma insistente tentativa de reparação dessa lacuna histórica, construída sob um cenário no qual cerca de $35 \%$ das pessoas que trabalham na área de ciências, tecnologia, matemática e engenharia são mulheres, enquanto apenas $15 \%$ dos estudantes em cursos de ciências da computação e engenharia no Brasil são mulheres, segundo levantamentos da UNESCO e da Sociedade Brasileira da Computação, sendo ainda mais complexo este cenário para pessoas não-brancas (MINAS QUE PROGRAMAM, 2020). Lembra-se que, especificamente nesta área comprometida com a computação e programação, há uma considerável demanda de trabalho que não exige formação acadêmica.

Nessa linha, ao lado de se compreender que muitas das integrantes desses grupos levados aos ambientes não têm a intenção de se aprofundarem na área da fabricação digital, visibiliza-se nesses espaços da rede, que reverberam geograficamente para o além-centro da metrópole, também uma potência promissora nesse sentido de capacitação dentro de estruturas presentes nas próprias comunidades. Apenas como adendo, soma-se que essas áreas de atuação de cunho tecnológico tendem a um crescimento ainda mais efetivo neste momento em que somos atravessados por uma era marcada pela intensa virtualização das experiências 
sociais, econômicas e educacionais (ainda mais aprofundadas pelo contexto atual de pandemia pelo qual passamos).

Então, movendo-se para além de um programa de formações e capacitações formais, pois uma das considerações saídas desse ciclo é a de que o processo em si evoca um grande potencial transformador para além dessa questão formativa (e do, por vezes polêmico, filtro empreendedor normalmente aplicado nestes espaços), é trazida a importância do grupo enquanto um organismo vivo e necessário à produção das experiências, composto por múltiplos agentes. Assim, faz sentido questionar a constante creditação do mundo maker com relação às premissas do novamente $D I Y$, transicionando para uma ideia que estaria, e muito, mais conectada com um fazer que em essência é subjacente, quando comparado às trocas reais tornadas possíveis pelo contato com um eu coletivo. Na agregação de uma terminologia importada, isto estaria mais conectado ao chamado DIT (Do It Together - Façamos Juntes), já relacionado como uma das palavras-chave do movimento por iniciativas e teorias da área. Assim, aqui também se provoca a atenção a uma discussão pertinente e presente nos campos da criação, relativa à sui generis figura desse criador ${ }^{\mathrm{xv}}$. A natureza individual da criatividade, segundo Buckley (1986), é uma categoria historicamente legitimada por tais narrativas centralizadas, e isto na área do Design cristaliza uma história do Design reduzida à história do designer - ou seja, de um dito sujeito essencial de tal processo. Entre tantos aspectos, tal movimento tende ao antagonismo de uma natureza complexa, que atua ao seu redor como componente essencial à moldagem dos trabalhos, atribuindo-lhes existência e significação antes, durante e depois dos processos de concepção (BUCKLEY, 1986).

Nessa esteira, visualizar o processo in loco como um ponto de convergência protagonizado por mulheres em apoio mútuo, mas movimentado também por outras estruturas de respaldo, fomenta esse questionamento do mito da unicidade criativa. Em tal vazão se evoca, para além do estado prático, também uma maior experiência de pertencimento dos envolvidos, importante aos fazeres daquele grupo em dado espaço. Assim, compreender que os modos normalizados e tidos como formais de pensar, conceber e criar estão estruturados nestes processos históricos moldados por narrativas predominantes que causam uma perturbação sobre o que há como validado ou não nestes percursos criativos, excluindo outras estruturas. Aqui cabem as reflexões de Grada Kilomba (2019) sobre os sistemas de colonização e validação da formação dos corpos de conhecimentos, a respeito de como as posições de autoridade hegemônicas criam marcadores de exclusão sobre o que é visto como adverso. Isso é dito devido ao fato de, por diversos momentos ali, naqueles ambientes, haver um certo questionamento a respeito daqueles nossos modos singulares de criação, por parte do grupo: um sentimento de falência do processo, discretamente, dava as caras quando as máquinas não eram operadas, os desenhos não eram concretizados e os comandos pareciam não ser inteligíveis ao grupo. No entanto, muitas outras estruturas e formas de construção coletiva eram mobilizadas o tempo todo para a realização das diversas outras partes dos projetos que excediam esse plano técnico-digital: a 'gambiarra', os 'palpites', as linguagens próprias, os espaços de recordação e afeto e as práticas caseiras eram lugares de favorecimento criativo nesses momentos.

No horizonte dessas situações, a bagagem acumulada da equipe da rede também trazia algo vital às práticas, que era a consciência de que aquela distância percebida sobre a etapa técnica era somente mais uma distância, e que todas elas faziam parte do processo de concepção do projeto. Não importava se as máquinas não conseguiam ser completamente controladas pelo grupo, pois, conforme já explanado, entendia-se a complexidade e o distanciamento daqueles sistemas. Uma das técnicas trouxe o exemplo dos bolsistas de um projeto municipal que trabalha com jovens em situação de vulnerabilidade social no local: "Eles fazem $20 \%$ da parte técnica, mas vêm cheios de ideias - e os processos nem sempre são rápidos". Ao se reconhecer 
Figura 3. Ana e seu filho Luís junto à técnica Tais em uma unidade da rede localizada na região central de São Paulo. Nesse momento eles desenvolviam um adaptador de talheres e pequenos objetos de manuseio cotidiano em um dos encontros.

esse aspecto, diálogos eram descortinados ao redor do tema e uma experiência de pertencimento poderia, então, ser construída.

Dentro de tal perspectiva visualizam-se essas porções do ciclo como eixos ativos, significativos e essenciais às diversas fases desse desenvolvimento, tentando descentralizar o pensamento quase mágico sobre a criação e a emergência da criatividade pautadas em um ator do processo - sem que isso se descole da ideia de autoria das mães sobre seus projetos. Decerto as mães e seus filhos ${ }^{\mathrm{xvi}}$ foram os autores e atores protagonistas de seus processos nessa longa jornada (Figura 03). Logo, nessa linha, concorda-se com Freire (2018) ao reconhecer que essas dimensões singulares propõem outras formas de análise crítica das significações por parte das porções engajadas. Assim, seguindo essa percepção, o processo ganha distintos contornos de totalidade: a partir do sentido de um novo nível vindo com esse devir há o refazer da consciência e compreensão da realidade, entendendo-se então como partes que se dialetizam e fundamentalmente colaboram com a construção (FREIRE, 2018).

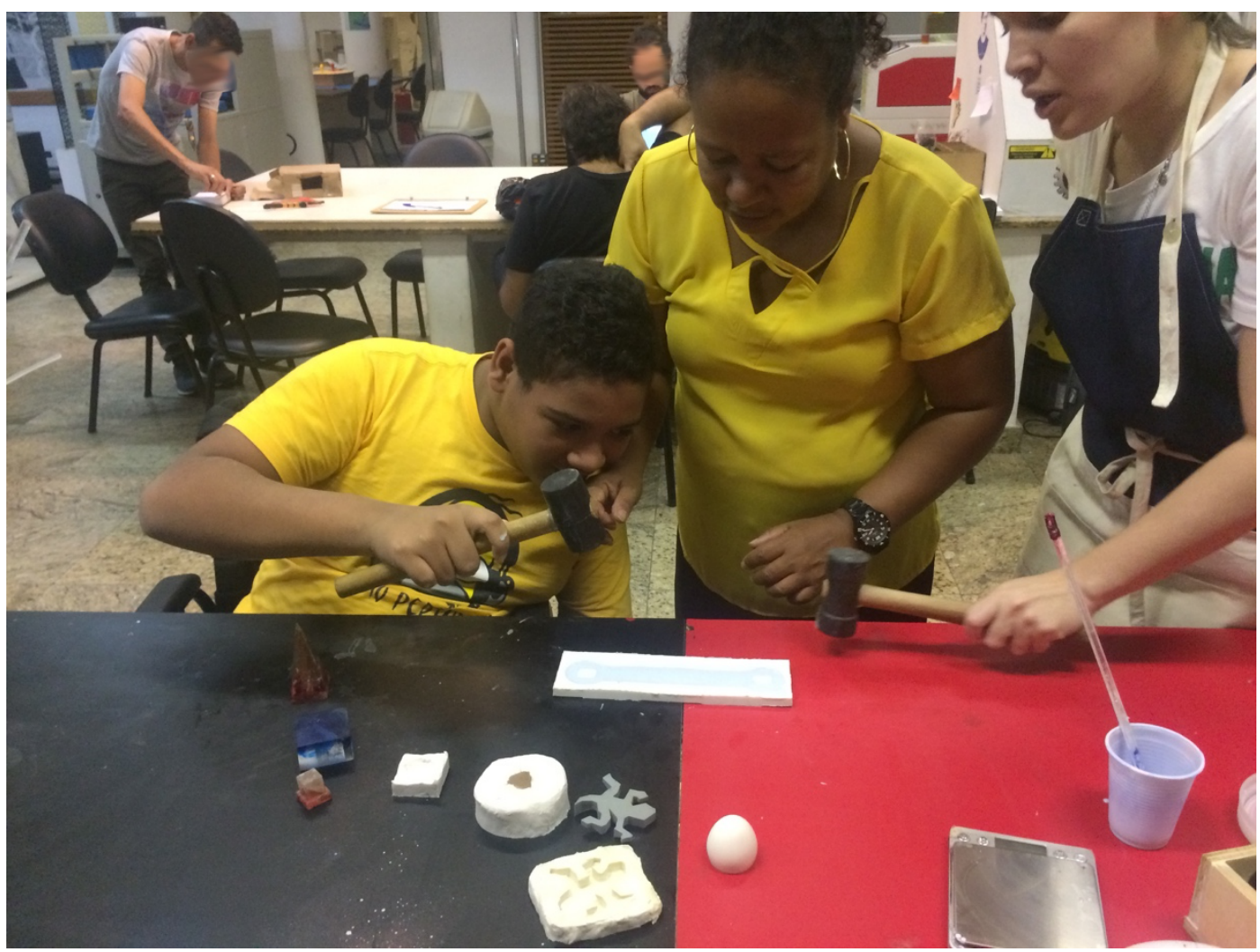

Tal câmbio de interpretação das performances dentro dos processos era notado ao, por exemplo, visualizarem-se trocas e devolutivas sobre as atividades mais críticas e propositivas ao longo dos encontros, apontando ponderações e adequações das práticas com pontuações voltadas às suas realidades. Isso também foi observado a partir da elaboração de propostas do grupo sobre as possibilidades de se trazerem os projetos de mulheres e crianças que não podiam estar ali presentes, e assim pensando coletivamente em estruturas de colaboração entre as mães. E então nesse local de mediação encontramo-nos mais uma vez com Freire: "estamos convencidos, pelo contrário, de que a reflexão, se realmente reflexão, conduz à prática" (FREIRE, 2018, p. 73). 


\section{CONSIDERAÇÕES FINAIS}

0 presente artigo trouxe considerações a respeito da etapa experimental realizada em uma pesquisa de doutorado, abordando a presença de mulheres-mães de crianças com deficiência em ambientes do tipo Fab Lab como desenvolvedoras de recursos de Tecnologia Assistiva em tais espaços. Esse recorte aqui exposto teve como objetivo refletir sobre os encontros e desencontros percebidos e relatados nesse percurso, explorando uma noção de distância como metáfora relacionada aos mecanismos dos processos realizados nos laboratórios.

A base empírica da pesquisa foi realizada na Rede Fab Lab Livre SP, uma rede pública de laboratórios de fabricação digital situada no município de São Paulo, durante aproximadamente dois anos. Entre os aspectos aqui mencionados, primeiramente deu-se destaque aos aspectos de territorialização e atenção à questão de ocupação desses espaços por parte de públicos que se distinguem do perfil dominante nesses ambientes. Em tal seara, foram discutidas estratégias e percepções desse grupo-usuário do ambiente, que foge ao estereótipo do frequentador desse tipo de local.

Como um segundo tópico levantado está o elemento de identificação desse grupo de mulheres com tais ambientes. Aqui buscou-se, através de dados, da exposição de projetos que dialogam com o tema e alicerçado também em conceitos freirianos, trazer a ideia de construção cotidiana e processos dialógicos, assim despertando o encorajamento, por parte das mulheres-mães, a mergulharem nesses laboratórios. Trabalhar com suas histórias e afetos, além das narrativas relacionadas à deficiência, tão conectadas as suas vidas de dedicação aos seus filhos, configuram-se como pilares fundamentais à identificação e criação de senso de pertencimento com relação ao curioso e novo universo com o qual passaram a ter contato.

Como um último ponto, buscou-se trazer a importância da coletividade como um elemento de travessia e aderência a esses grupos, em trabalho nesses locais. A experiência comunitária e colaborativa figura como matéria fundamental da experiência das mães, sem que isso interfira em aspectos relacionados à autoria ou originalidade de seus projetos. Nessa linha, o aspecto fundamental da deficiência é trazido à luz, o qual é composto pela tônica de sua singularidade. Com isso cada projeto, ao mesmo tempo que é único, próprio e adaptado a cada filho das mulheres-mães em cena, também consta de muitas mãos em sua constituição. Frisa-se que, entre mães e mãos, o aprendizado sobre esse processo, que nem sempre é constante ou linear, também é entregue à rede. Dessa forma, através desse tipo de experiência também importa trazer cenários à rede, evidenciando a essencialidade de políticas locais que valorizem a pluralidade e potência do coletivo como impulso fundamental à construção de novas narrativas e capacidades transformadoras dentro desses equipamentos, que desde já elucidam impactos positivos e aspectos desafiadores. Como sugestão a futuras pesquisas e abordagens sobre o tema, fica o caminho a ser percorrido por entre aspectos que abordem a presença desse corpo coletivo plural nestes ambientes e seus processos realizados nas atividades de desenvolvimento de projetos e produtos.

\section{Agradecimentos}

Os pesquisadores agradecem a Coordenação de Aperfeiçoamento de Pessoal de Nível Superior (CAPES) pelo apoio financeiro à pesquisa, à Rede Fab Lab Livre SP pelo apoio às práticas, à ONG e às mães que participaram dos processos de pesquisa. 


\section{Referências Bibliográficas}

BERSCH, R. Introdução à Tecnologia Assistiva. Porto Alegre: Assistiva - Tecnologia e Educação, 2017.

BUCKLEY, C. Made in Patriarchy: toward a Feminist Analysis of Women and Design. Design Issues, v. Vol. 3, n. No. 2, p. pp. 3 - 14, 1986. DOI: https://doi.org/10.2307/1511480

CHIOVETTI, S. P. Inovação nos Serviços Públicos na cidade de São Paulo (2013-2016). São Paulo: Fundação Perseu Abramo. 136 p, 2017.

CRUZ, D. M. C.; EMMEL, M. L. G. Uso e abandono de Tecnologia Assistiva por pessoas com deficiência física no Brasil. Revista Digital, Buenos Aires, ano 17, n. 173, 2012.

FAB FOUNDATION. Fab Lab Network. S/d. Disponível em: https://fabfoundation.org/globalcommunity/\#: :text=More\%20than\%201\%2C750\%20Fab\%20Labs\%20all\%20over\%20the\%20globe!\&text=Bec ause\%20all\%20Fab\%20Labs\%20share,laboratory\%20for\%20research\%20and\%20invention. Acesso em: 19 jan. 2021.

FAB LAB RECIFE. Movimento Mulheres Maker. Disponível em: https://www.fablabrecife.com/o-quefazemos/inovacao-maker/movimento-mulheres-makers/. Acesso em: 20 jan. 2021.

FAULKNER, W. The Technology Question in Feminism: a view from feminist technology studies. Women's Studies International Forum, Vol. 24, No. 1, pp. 79-95, 2001. DOI: https://doi.org/10.1016/S0277$\underline{5395(00) 00166-7}$

FREIRE, P. Pedagogia da Autonomia: Saberes necessários à prática educativa. São Paulo: Paz e Terra, 1996. p. 54

FREIRE, P. Pedagogia do Oprimido. Rio de Janeiro/São Paulo: Paz e Terra, 2018.

GERSHENFELD. N. How to Make Almost Anything: the digital fabrication revolution. Foreign Affairs, 91, n. 6, p. 43-57, 2012.

HAMIDI, F. et al. Participatory Design of DIY Digital Assistive Technology in Western. In: Proceedings of 2nd African Conference for Human Computer Interaction (AfriCHI'18), 2018. DOI:

https://doi.org/10.1145/3283458.3283478

IBGE - Instituto Brasileiro de Geografia e Estatística. Censo Demográfico 2010. Resultados gerais da amostra. Rio de Janeiro: IBGE, 2012.

ITS BRASIL. Instituto de Tecnologia Social. S/d/ Disponível em: http://itsbrasil.org.br/ Acesso em: 18 jan. 2021.

KILOMBA, G. Memórias da Plantação: episódios do racismo cotidiano. Rio de Janeiro: Cobogó, 2019.

LAMB, M. E.; BILLINGS, L. A. L. Fathers of children with special needs. In: M. E. Lamb. (Org.). The role of the father in child development. London: John Wiley \& Sons, 1996. P. 179-190.

MINAS QUE PROGRAMAM. Minas que Programam. Disponível em: <https://minasprogramam.com/>. Acesso em: 20 jan. 2021.

Juliana Maria Moreira Soares julianammsoares@gmail.com

Paulo Eduardo Fonseca de Campos pfonseca@usp.br
MENA, F. "Pandemia é resposta biológica do planeta", diz físico Fritjof Capra. Folha de São Paulo. 2020.

Disponível em: https://www1.folha.uol.com.br/fronteiras-do-pensamento/2020/08/pandemia-e-respostabiologica-do-planeta-diz-fisico-fritjofcapra.shtml?pwgt=17kor9scpvbavbfwzz9yt5f9nubbig22crukp5g9uls7p2wy\&utm source=whatsapp\&utm med ium=social\&utm_campaign=compwagift\&fbclid=IwAR309BpFcZrzyrv7TfBToFxEq1nbFakS9SPCL 070h12As3fYyh0GUczPM. Acesso em: 10 jan. 2021.

PERROT, M. Minha história das mulheres. São Paulo: Contexto, 2007.

PRETALAB. Pretalab. Disponível em: https://www.pretalab.com/. Acesso em: 20 jan. 2021. 
VENDRUSCULO, L. E. B. A descoberta da deficiência do filho: o luto e a elaboração dos pais. 2014, $34 \mathrm{f}$. Monografia (Bacharelado em Psicologia) - Departamento de Humanidades e Educação, Universidade Regional do Noroeste.

\section{Notas}

' O capacitismo é um conceito relacionado à discriminação de pessoas com deficiência. No sistema em que se opera o capacitismo existiriam as "normalidades", ou seja, corpos e mentes vistos como "aptos", que seriam as pessoas sem deficiência. Sua participação em atividades da vida cotidiana em quaisquer campos que sejam não é vista com restrições ou preconceitos por conta dessa corponormatividade. Porém o contrário se mobiliza para a pessoa com deficiência, que é estigmatizada e excluída dos processos sociais. Assim, é possível de se enxergar que são múltiplos os arranjos da sociedade que são capacitistas.

ii Trata-se de um evento realizado através da Secretaria Municipal de Inovação e Tecnologia da Prefeitura de São Paulo e da Rede Fab Lab Livre SP, o qual disponibiliza uma série de workshops, palestras e demais atividades relacionadas à cultura da fabricação digital. Sua última edição foi no ano de 2019, tendo três edições até o momento.

iii Aqui fala-se da divisão que se constrói a partir das performances de gênero nas sociedades.

iv Conforme já exposto, aqui se fala em multiplicidade pelo fato de, apesar de falarmos de mulheres-mães de crianças com deficiências, não-brancas e moradoras de regiões periféricas de uma metrópole, também falarmos de um grupo bastante heterogêneo, constituído por integrantes com histórias e trajetórias distintas entre si.

${ }^{\vee}$ Disponível em < https://girlswhocode.com/ > . Acesso dia 20 de janeiro de 2021.

vi Disponível em < https://minasprogramam.com/ >. Acesso dia 20 de janeiro de 2021.

vii Disponível em < https://www.pretalab.com/ > . Acesso dia 20 de janeiro de 2021.

viii Na página web do Fab Lab Recife também há um material audiovisual explicativo sobre a iniciativa. Disponível em < https://www.fablabrecife.com/o-que-fazemos/inovacaomaker/movimento-mulheres-makers/ >. Acesso dia 20 de janeiro de 2021.

ix Entende-se por práticas tão profundamente arraigadas no tecido social, as quais por vezes já quase não somos mais capazes de perceber ou questionar seus conteúdos, mesmo integrando os grupos de opressão (a exemplo de uma mulher cometendo atitudes que podem ser lidas como machistas em determinado contexto). Dessa forma, emerge a essencialidade dessas atividades informativas e reflexivas ao lado das atividades técnicas de formação.

* O Clube de Marcenaria das Minas é um espaço voltado à criação de e com mulheres, que tem encontros quinzenais aos sábados. Disponível em: $<$ http://fablablivresp.art.br/cursos/curta/clubede-marcenaria-das-minas-0 >. Acesso em: 20 jan. 2021.

${ }^{x i}$ O Instituto de Tecnologia Social - ITS Brasil - é uma organização da sociedade civil de interesse público a qual implementou a Rede Fab Lab Livre SP através de um edital público promovido pela Prefeitura de São Paulo. Para além da implementação dos laboratórios, o ITS Brasil também é responsável pela gestão de toda a rede.

xii O Emprego Apoiado trata-se de uma metodologia estadunidense que se desenvolve a partir de um conjunto de ações voltadas à preparação e inserção no mercado de trabalho por parte da pessoa com deficiência e em outras condições de vulnerabilidade, sempre orientada por acompanhamento especializado. O ITS Brasil realiza práticas dentro desta linha em seus projetos, como na Rede Fab Lab Livre SP (ITS BRASIL, s/d).

xiii Reportagem disponivel em: https://www1.folha.uol.com.br/fronteiras-dopensamento/2020/08/pandemia-e-resposta-biologica-do-planeta-diz-fisico-fritjofcapra.shtml?pwgt=17kor9scpvbavbfwzz9yt5f9nubbig22crukp5g9uls7p2wy\&utm_source=whatsapp \&utm_medium=social\&utm_campaign=compwagift\&fbclid=IwAR3o9BpFcZrzyrv7TfBToFxEq1nbFakS9SPCL_070h12As3fYyhOGUczPM. Acesso em: 20 jan. 2021.

xiv Do inglês, genderizing, nesse contexto lendo as estatísticas com esse recorte de gênero nos números observados.

Gestão \& Tecnologia de Projetos 
${ }^{x v}$ Aqui no masculino fazendo referência à historização mais frequente das narrativas, que é do homem em tal posição histórica de gênio/criador único na área (BUCKLEY, 1986).

xvi Esclarece-se aqui que a proposta fundamental do projeto era que as crianças participassem ativamente das atividades, afinal, os recursos seriam moldados para e por elas próprias. No entanto, apesar dos esforços da coordenação da Rede, não foi possível obter o transporte público especial para que os filhos pudessem estar presentes nas oficinas. A dependência de transporte público e o uso de tecnologias assistivas como cadeiras de rodas são fatores que resultam em dificuldade de locomoção para as mães, a exemplo da ida aos laboratórios. Dessa forma, adaptamos os procedimentos para que houvesse interação das crianças com os produtos e sinalizamos à Rede a necessidade de se provocarem diálogos entre as secretarias relacionadas às instâncias, visando gerar acessibilidade e uma melhoria nessa espécie de atendimento. 